\title{
Micro-Electro Discharge Machining of Holes and Grooves: AnAssessment of Process Parameters
}

\author{
Sasmita $\mathrm{Bal}^{\# 1}$, Purna Chandra Mishra ${ }^{\# 2}$, Ashok Kumar Satapathy ${ }^{* 3}$ \\ \# Thermal Research Laboratory, School of Mechanical Engineering, \\ KIIT University, Bhubaneswar- 751024, Odisha, India \\ ${ }^{1}$ sasmitabal@gmail.com \\ ${ }^{2}$ pcmishrafme@kiit.ac.in \\ * Department of Mechanical Engineering, NIT, Rourkela-769008, Odisha India \\ 3aksatapathy@nitrkl.ac.in
}

\begin{abstract}
The need for a better cooling purpose in bio medical, electronics, microprocessors and radars has attracted many researchers. Since, microchannels fulfil this objective it's machining through different micro machining techniques requires more skill and knowledge. Micro electrical discharge machining (EDM)is considered as one of the advanced methods of machining micro tools, dies, channels, grooves etc. More emphasis should be given to this machining process so that complicated geometries with least effort can be produced. In the present work critical study has been done on different tool materials as well as workpiece materials used on machining work table in micro EDM with different new strategies of machining will be helpful to enhance understanding of the subject. Along with this a direct method of getting tools for making micro holes and grooves on workpiece is suggested.
\end{abstract}

Keyword-Microchannel, tool electrode, microholes, microgrooves, material removal rate, tool wear

\section{INTRODUCTION}

In recent years micro-electro discharge machining(EDM) gained a significant role in fabrication of very complex microstructures like micro holes, channels, grooves and 3-D structures irrespective of the hardness of the workpiece material [1]. This technology helps to remove micro particles easily from electrically conductive materials due to generation of spark which associated with melting and vaporization of materials from the surface of workpiece [2].As it is a contactless process that exerts very small force on both electrode and specimen, it minimizes the chances to develop thermal stresses. The major difference between macro and micro electro discharge machining is well defined by the plasma size[3]. $\mu$ wire EDM, $\mu$-die sinking, $\mu$-milling and drilling are the different varieties of micro EDM with respect to tool and tool kinetics[4].In micro wire EDM the electrode used is either tungsten or copper wire of diameter $25-300 \mu \mathrm{m}$ that cut through the specimen where as in micro die sinking EDM the tool electrode is the replica to be produced in workpiece[5]. To get a fine electrode, reverse polarity is done where material generally gets removed from electrode instead of workpiece. This process generally called as wire electro discharge grinding or WEDG. After getting desired shape of electrode by WEDG that can be used to drill small hole on workpiece called EDM drilling. In EDM milling cylindrical electrode is rotated which follow a path through the workpiece to produce required geometry. Micro EDM is the machining on EDM where sizes of the tool, discharge energy are in micro levels[6]. There are large research possibilities in this area as it has very wide applications[7].

Micromachining in EDM has been extensively studied by many researchers and presented in $[8,9,10]$. Sato $e t$ al [11] were the first to propose micro hole drill by EDM for ink-jet nozzles of printers. The holes produced are of diameter 15 to $300 \mu \mathrm{m}$. In addition to micromachining microelectrodes can be generated by wire electro discharge grinding (WEDG) $[12,13]$.Tungsten electrodes with diameter $300 \mu \mathrm{m}$ were machined to form $200 \mu \mathrm{m}$ using WEDG to produce microstructures on single crystal P-type boron doped silicon as it is widely used in semiconductors [14]. Masuzawa et al [15] proposed a system for drilling microholes by EDM. Anew technology is developed where micro holes and shafts are produced of $5 \mu \mathrm{m}$ in diameter [16].Different materials used as electrodes in EDM are of different shapes of copper,tungsten,graphite, silver and brass[17,18]. Mohite et al [19] developed a EDM tool for fabrication of leaf shape microchannel heat sink of Aluminium 6061 and optimize the process parameters by using orthogonal array Taguchi's analysis of variance (ANNOVA) and signal to noise ratio (S/N ratio).Yan et al [20] found fabrication of tool electrode for micro hole fabrication by die sinking EDM as the most difficult job. An experimental procedure is followed by them to get a small, fine and straight cupper tool electrode to make micro holes in carbide workpiece.Yu et al [21] modified commercial EDM machine to get planetary motion of tungsten electrode used as tool to produce high aspect ratio micro holes and blind non circular holes on stainless steel AISI 304L workpiece material and at the same time blind triangular, square,pentagonal micro holes are achieved by offsetting the tool path by 15 to $20 \mu \mathrm{m}$. Jahan et al [22] 
compared surface finish produced by micro EDM on WC material using $\mathrm{CuW}, \mathrm{W}$ and $\mathrm{AgW}$ electrodes. As electrode surface finish reflected on workpiece material the electrode was sliced and dressed by scanning micro EDM to remove the rough electrode surface. $\mathrm{AgW}$ shows better surface finish as electrode for micro EDM of WC [23].Micro EDM has done many challenging job like producing fine micro holes in tough materials like high nickel alloy using tungsten carbide as tool [24,25]. Gosavi et al [26] investigates micro EDM of titanium wrought alloy (VT-20) which is mostly used in aerospace using rotary brass hollow tubular electrode. Rajurkar et al [27] generated complex 3D micro cavities using conventional EDM integrated with CAD/CAM with simple shaped electrodes mounted on it. Ishida and Takeuchi [28] proposed a trajectory EDM technique to make L-shaped curved hole without going for conventional drilling. Heeren et al concluded that complicated 3D structures can be generated by micro EDM with small size electrodes [29]. Micro electrode arrays generated by wire EDM and followed by chemical etching process found to be more challenging to record neural activities [30]. Single and multi channel tubular brass and copper electrodes were used for fast hole drilling in Inconel 718 and Ti-6Al-4v materials used in aerospace [31].Wang et al [32] compared stationary, rotational and rotational with eccentric through hole electrodes mounted in micro EDM in terms of material removal rate (MRR) and electrode wear rate (EWR) and concluded rotational with eccentric through hole has highest MRR and EWR. It is possible to control and measure dimension of thin electrode by optical sensor developed by Lim et al [33] during tool fabrication so that high aspect ratio micro structures can be produced using micro EDM. Cemented tungsten carbide of fine particles is found to be better tool compared to cemented tungsten carbide (WC) and tungsten (W) which is generally used in micro-EDM [34]. In some experimental work micro tool is fabricated by (WEDG) combined with ultrasonic vibration by helical micro tool electrode to drill and finish micro holes $[35,36]$. In one of the experiment micro spherical diamond tool is built by EDM and used to make micro spherical cavity in a high nickel alloy [37]. A micro tool of diameter $100 \mu \mathrm{m}$ was fabricated by (WEDG) over which $\mathrm{SiC}$ particles are coated by electrophoretic deposition (EPD) and used to polish microholes in quartz with the help of ultrasonic vibration machining (USM) [38].Using Tungsten carbide cylindrical rod of diameter $300 \mu \mathrm{m}$ as tool electrode micro EDM milling was done directly to get desired slots on stainless steel AISI420 avoiding the need to fabricate complex tools separately [39]. Wenget al [40] proposed a micro EDM process using multi electrodes for batch production of micro parts. Here multi electrodes of 16 pieces in $1.5 \mathrm{~mm}$ diameter were fabricated by wire-EDM using Tungsten carbide as electrode by adapting electrode rotating mechanism on work plane.Further, this helps to process micro slots in copper plate using positive polarity machining.Uhlmannet al [41] proposed method to machine micro parts in micro-EDM which was act as die for micro structure batch production. An array of 400 Copper electrodes of diameter $20 \mu \mathrm{m}$ which was fabricated by LIGA method to avoid the constraints for making multi electrodes was utilized for the batch production of arrays of holes on $50 \mu \mathrm{m}$ stainless steel $[42,43,44]$. EDM block electrode method was used to precisely fabricate cylindrical stepped section microelectrodes of diameter $20 \mu \mathrm{m}$. This technology is further extended with some new strategies to fabricate tapered, circularly stepped, rectangular and triangular symmetrical section electrodes which further used to produce micro features in $200 \mu \mathrm{m}$ thickness stainless steel [45,46]. Chen [47] used wire EDM technology to drill mass micro holes of high aspect ratio in Tungsten carbide of $800 \mu \mathrm{m}$ diameter which will act as electrode to form arrays of holes precisely by upward batch micro EDM technique on stainless steel plate. As conventional WEDG requires more time to shape micro tool as rough and finish machining steps are associated with this, a twin wire EDM is proposed which is used to fabricate micro tool electrode of tungsten carbide of diameter $0.02 \mathrm{~mm}$ and length $0.73 \mathrm{~mm}$ [48].

In some cases WEDG combines with one pulse electro discharge to fabricate micro spherical probes and cavities [49].Micro holes can be fabricated more economically using copper and its alloy as electrode suggested by Kaminski et al [50]. A modified volume removal per discharge approach is taken into consideration to control electrode wear in $\mu$ EDM drilling [51,52]. Present work focuses on micro EDM die sinking and the different types of electrodes used to get complex microstructures with ease and less fabrication time.

Although numerous research has been done on machining parameters during micro EDM no investigation is done on electrode shape and materials used in different micro EDM machining. In the present work critical study has been done on different tool materials as well as workpiece materials used on machining work table in micro EDM with different new strategies of machining will be helpful to enhance understanding of the subject. Along with this a direct method of getting tools for making micro holes and grooves on workpiece is suggested.

\section{EXPERIMENTAL METHOD}

\section{A. Selection of tool and workpiece material}

Owing to the increased development in the field of EDM processes, it has now become essential to figure the best tool material for higher material removal rate, lower tool wear rate and improved surface finish. In this work, copper winding wire and copper flat plate were taken as tool electrodes for the aluminum alloy workpiece.

Winding wire of copper of dimension $0.5 \mathrm{~mm}, 0.3 \mathrm{~mm}$ upto $0.1 \mathrm{~mm}$ in diameter are available in the market with very cheap cost. In current experiment $0.54 \mathrm{~mm}$ winding wire is taken into account as no special attachment is considered to hold it to minimize the cost. Micro drill chalk can be used to hold the lesser diameter wires firmly. 
The second one is the cupper plate of thickness $0.23 \mathrm{~mm}$ which is again available very easily. The geometric shape of wire electrode is maintained in two different aspects i.e. its length and its roundness. The roundness of the structure is maintained to get the holes in a complete desired shape.

Aluminum 6061-T6 (Al 6061- T6) is selected as workpiece material for the experiment which is very general in use. Aluminium is about three times as thermally-conductive as steel. This characteristic is important in heatexchange applications (whether heating or cooling). This also makes it best for being easily fabricated into various forms such as foil, sheets, geometric shapes, rod, tube and wire. Properties of tool and workpiece material are summarized in Table 1.

TABLE I. Properties of tool and workpiece material

\begin{tabular}{|l|l|l|}
\hline \multicolumn{2}{|c|}{ Properties of Material } \\
\hline & \multicolumn{1}{|c|}{ Work piece( Al 6061- T6) } & Tool (Cu) \\
\hline Composition (\%) & $\begin{array}{l}\mathrm{Al}(95.8-98.6), \mathrm{Cr}(0.04-0.35), \mathrm{Cu}(0.15-0.4), \mathrm{Fe}(\max .0 .7), \\
\mathrm{Mg}(0.8-1.2), \mathrm{Mn}(\max .0 .15), \mathrm{Si}(0.4-0.8), \mathrm{Ti}(\max .0 .15), \mathrm{Zn} \\
(\text { max.0.25), other 0.15 }\end{array}$ \\
\hline Density $\left(\mathrm{g} / \mathrm{cm}^{3}\right)$ & 2.7 & 8.96 \\
\hline Melting point $\left({ }^{\circ} \mathrm{C}\right)$ & $582-652$ & 1083 \\
\hline Specific Resistance $(\mu \Omega \mathrm{mm})$ & $37-40$ & 17.4 \\
\hline
\end{tabular}

\section{B. Preparation of the tool}

From the winding wire of diameter $0.54 \mathrm{~mm}$, a $5 \mathrm{~cm}$ length is snipped off. From the upper layer, the lamination is removed by using 1000 grade sand paper. The wire or electrode is rolled precisely to make it straight so that it can penetrate directly over the marking done on the workpiece. In similar manner, copper electrode is prepared. Fig. 1 shows types of electrodes considered in the experiment.

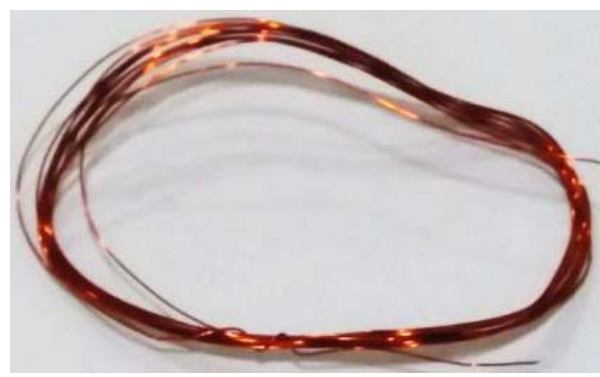

(a)

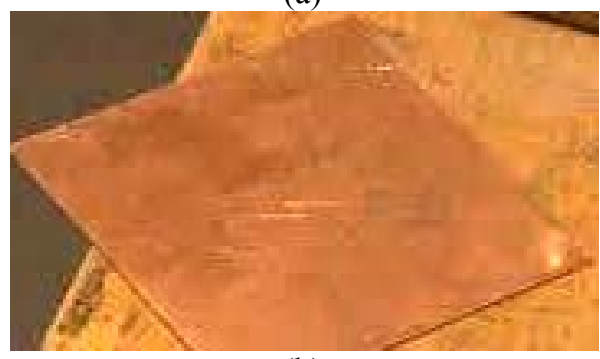

(b)

Fig. 1.Types of electrodes (a) copper wire with circular cross-section(b) Copper wire cut from plate with rectangular cross-section

\section{Work piece preparation}

The workpiece of rectangular cross-section of the required dimension $(25.09 \mathrm{~mm} \times 12.6 \mathrm{~mm} \times 4.09 \mathrm{~mm})$ for micro hole fabrication and $(23.5 \mathrm{~mm} \times 11.8 \mathrm{~mm} \times 4.28 \mathrm{~mm})$ for groove fabrication are cut from an aluminum bar shown in Fig.2. 


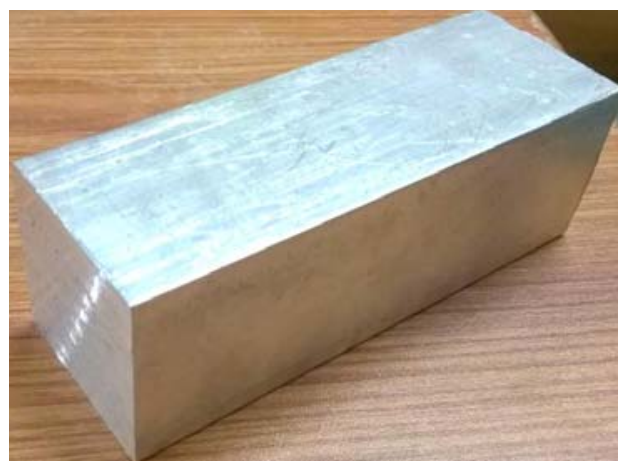

Fig. 2.Aluminum square bar used as work piece material

The marking of all the dimensions in completed with the help of a marker. This step is necessary to avoid inaccuracy of dimensioning. After the roughly cut workpiece is available to us, it is important to grind the surface to not avoid any corroded part left on workpiece. Each surface of workpiece is well-grinded. To give a final smooth surface to the workpiece so that the micro holes can be perfectly machined without any error, polishing is done. The above step by step process makes the base of workpiece ready to be machined. Now, after getting an error-free base, an exact position of all the four holes are marked. This positioning is so done that every hole is equi-distant to each other. As the cross-section of workpiece is rectangular, the margin of holes from both the end is set as $1 \mathrm{~mm}$. The holes are positioned diagonal to each other in a zigzag manner. The workpiece is then ready for machining. Fig.3 depicts CAD model for machinedmicro holes and micro grooves respectively.

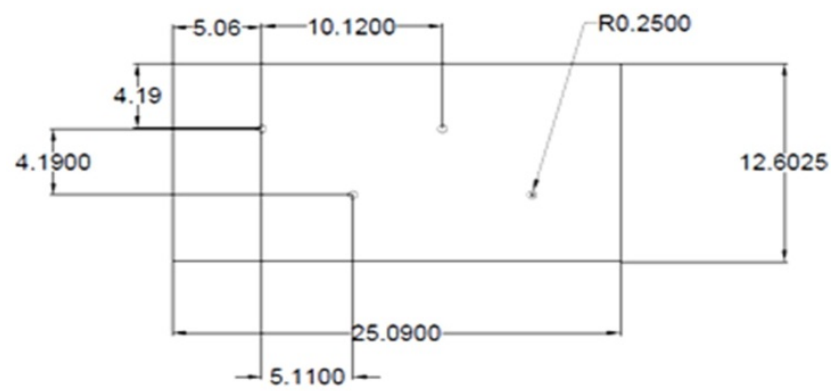

(a)

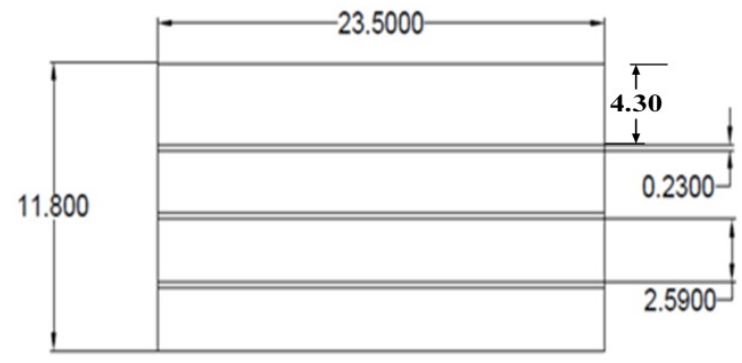

(b)

Fig.3.Machining configurations of (a) micro holes and (b) micro grooves (all dimensions are in $\mathrm{mm}$ )

\section{Electro-discharge machining setup}

The experimentsare conducted using die sinking electro discharge machine of type Electronica smart ZNC series. The machine has a table of rectangular shape to hold the job. The electrode is to be fixed in the tool holder above the work piece and vertical feed can be given to have desired cavity in the work piece.The workpiece is firmly held on magnetic base. Here, direct polarity is taken into consideration where workpiece is connected to positive terminal and simultaneously tool is connected to negative terminal. Fig.4 and Fig. 5 show the experimental setup of EDM where experiment is carried out for micro holes and rectangular grooves respectively.Considering good wetting property, stable dielectric strength, low viscosity, higher flash point, chemically neutral to work piece as well as electrode, pleasant odour and easy availability EDM oil is selected as dielectric fluid for the present experiment. 
Table 2 shows specification of Electrol EDM oil that fulfils above requirements and gives optimum performance of the machine. In order to avoid spark between electrode and debris formed from machining effective flushing is used but as the fabrication is in micro structure the pressure of flushing is also a main parameter that affects the geometry. So, flushing pressure is kept minimum about $0.1 \mathrm{~kg} / \mathrm{cm}^{2}$ by set of two nozzles.

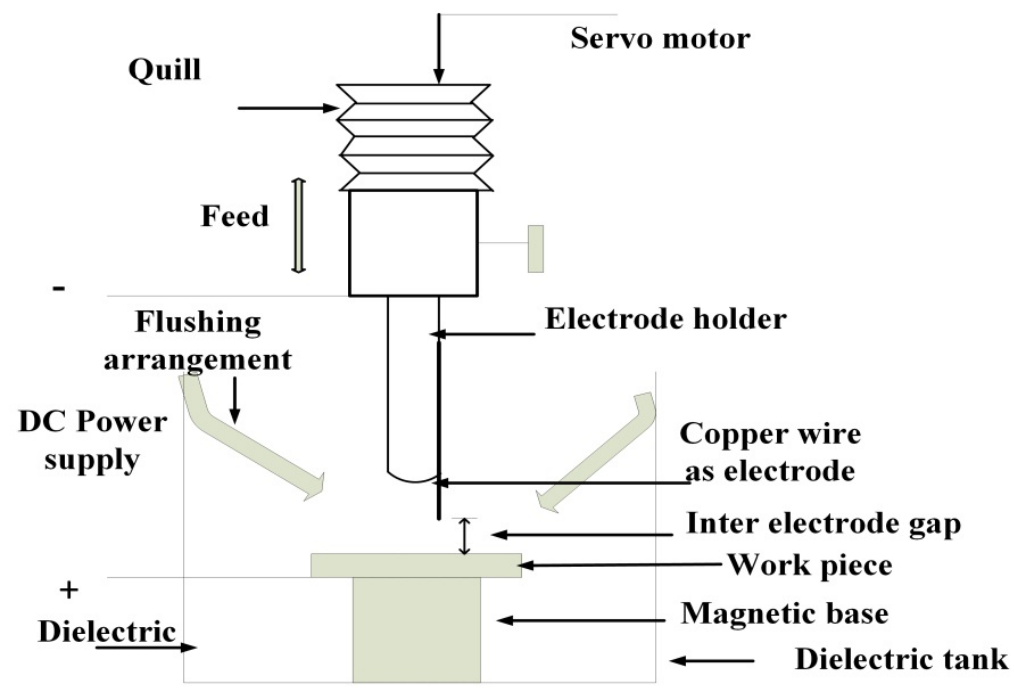

Fig. 4.Electro-discharge machining setup for micro holes

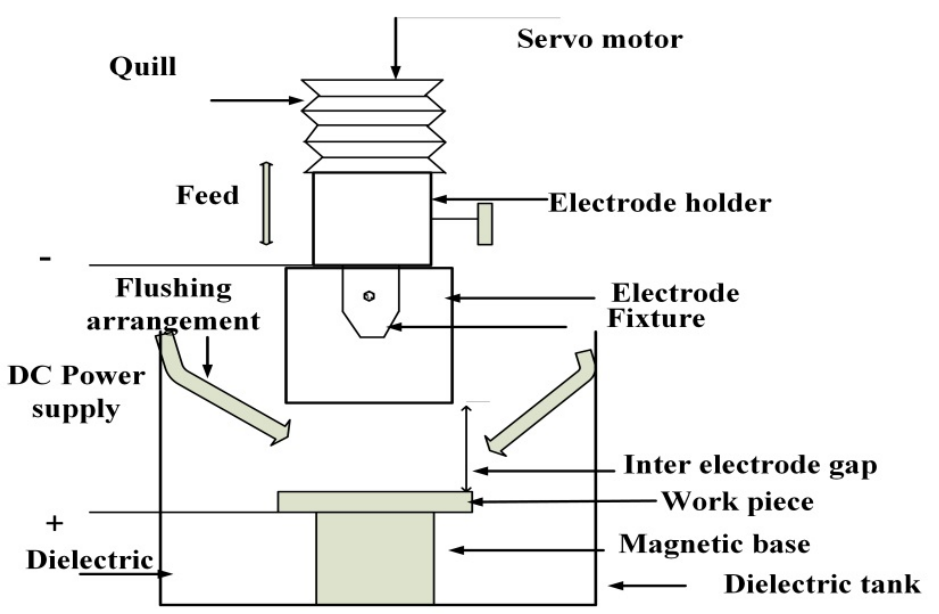

Fig. 5.Electro-discharge machining setup for micro grooves

TABLE II. Specification of EDM oil.

\begin{tabular}{|l|l|}
\hline Characteristics & Values \\
\hline Density at $30^{\circ} \mathrm{C}$ & $0.78+/-0.2$ \\
\hline Flash point ${ }^{\circ} \mathrm{C}$ & $105^{\circ} \mathrm{C}$ \\
\hline Pour point ${ }^{\circ} \mathrm{C}$ & $-9{ }^{\circ} \mathrm{C}$ \\
\hline Viscosity cSt at $38^{\circ} \mathrm{C}$ & $2.16 \mathrm{cs}$ \\
\hline Copper corrosion & $<1$ \\
\hline Dielectric strength $\mathrm{Kv}$ min & 45 \\
\hline
\end{tabular}

Both types of the electrodes are fixed to the end of the quill with a clamping device during their respective operations. For making the circular holes winding wire of $5 \mathrm{~cm}$ length of dia. $0.54 \mathrm{~mm}$ is fixed tightly to the side of a cylindrical tube whereas for groove a special type clamping device is used to hold the cupper plate firmly. Auto positioning is done to make it sure that the tool touches the previously marked point where cavity is required to generate and spark will propagate through that point. 
Aligning of workpiece is done to bring it to a defined position with respect to table. Generally it is fixed at the middle of the table. Alignment is done with respect to $\mathrm{X}$ and $\mathrm{Y}$ axes with the help of dial gauge. Workpiece is hold firmly to a special attachment. The screw of the attachment is tightened properly so that it should not vibrate during the experiment. The workpiece is positioned according to the tool.

\section{E. Experimental process parameters}

After fixing tool and workpiece in its proper position machine variables are fixed. To know the effect of changing current on fabrication two different current of $1.5 \mathrm{~A}$ and $1 \mathrm{~A}$ has been taken into consideration. Apart from this other machining parameters that have been selected are listed in Table 3. Sensitivity (SEN) parameter controls voltage drop by the parameters due to improper flushing whereas anti-arc sensitivity (ASEN) value is come into action when carbon formation during machine will move from work-piece to tool.

TABLE III. Machining parameters and their values

\begin{tabular}{|l|c|c|c|}
\hline \multicolumn{4}{|c|}{ Control parameters } \\
\hline Parameters & Symbol & Value & Unit \\
\hline Pulse on time & $\mathrm{T}_{\text {on }}$ & 50 & $\mu \mathrm{S}$ \\
\hline Discharge current & $\mathrm{I}_{\mathrm{P}}$ & $1.5 / 1$ & $\mathrm{~A}$ \\
\hline Tool lift time & $\mathrm{t}$ & 6 & $\mathrm{Sec}$ \\
\hline Tool work time & $\mathrm{Tw}$ & 3.1 & $\mathrm{Sec}$ \\
\hline Flushing pressure & $\mathrm{F}$ & 0.1 & $\mathrm{Kgf} / \mathrm{cm}^{2}$ \\
\hline \multicolumn{5}{|c|}{ Fixed parameters } \\
\hline Gap Voltage & $\mathrm{V}$ & 50 & $\mathrm{~V}$ \\
\hline Sensitivity & SEN & 6 & \\
\hline Anti-arc sensitivity & ASEN & 3 & \\
\hline
\end{tabular}

III. RESULTS AND DISCUSSION

To verify the effect of changing of current on holes images are taken using scanning tunneling microscope (STM) and scanning electron microscope (SEM). Fig. 6 shows microscopic view of microholes at $1.5 \mathrm{~A}$ machining condition.

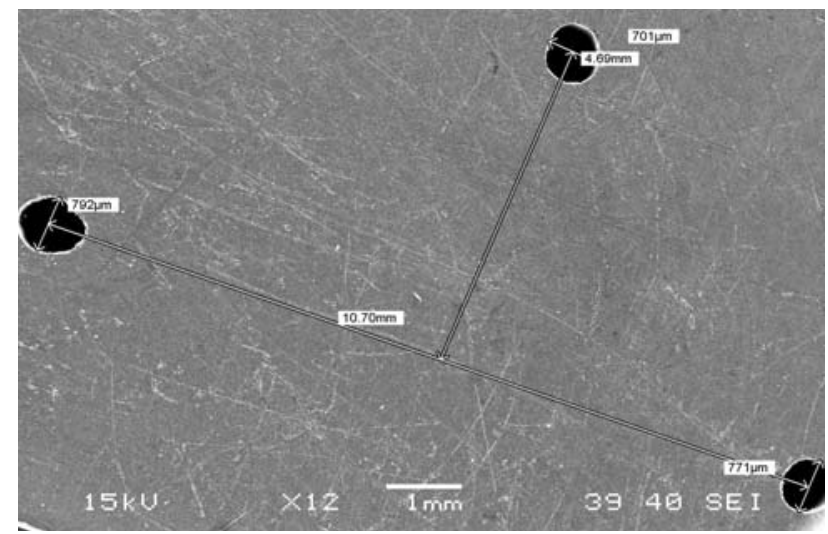

Fig. 6.Scanning electron micrograph of upper surface with three consecutive hole on the workpiece at $1.5 \mathrm{~A}$ current

First the upper surface of holes produced at 1.5A and $1 \mathrm{~A}$ currentsare analysed by Scanning Electron Microscopy (SEM). The scanning electron micrographsof both the workpiece are depicted in Fig.7. 


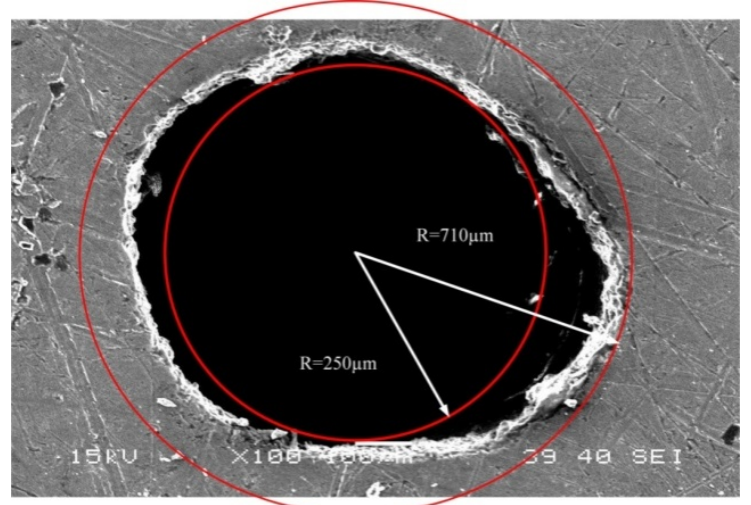

(a)

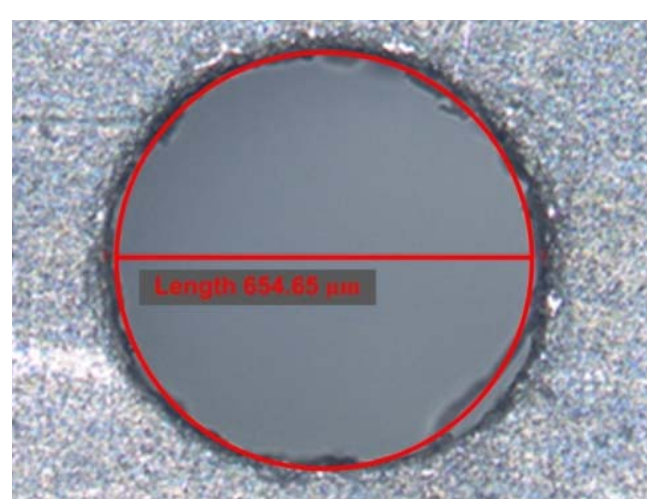

(b)

Fig. 7.Scanning electron micrographs of surface of hole at gap voltage $50 \mathrm{~V}$ and pulse on time $50 \mu \mathrm{s}$ (a) $1.5 \mathrm{~A}$ current and (b) $1.0 \mathrm{~A}$ current

Surface finish in terms of burr free surface can be visualized from Fig. 7. This might be due to the fact that with increase in current, spark intensity increases resulting in melting and evaporation from the work piece. With increase in pulse on time keeping voltage gap and current constant at low level gives low material removal rate. Tool wear increases to a maximum value then decreases with resulting in less machining time and poor surface finish . So, pulse on time is kept minimum during the experiment.

The holes are analyzed by considering diametrical overcut and taper angle. Diametrical overcut and taper angle can be found using Equation (1) and (2) respectively.

Overcut $=\frac{(\text { Average diameter of hole after machining })-(\text { Diameter of the tool used })}{2}$

Taper Angle $=\tan ^{-1}\left[\frac{(\text { Entrance diameter- Exit diameter })}{2 \times \text { Machined depth }}\right]$

$\operatorname{MRR}$ per hole $\left(\mathrm{mm}^{3} / \mathrm{min}\right)=\frac{1000 \times \text { Weight loss }(\mathrm{gm})}{\text { Metal density }\left(\mathrm{gm} / \mathrm{cm}^{3}\right) \times \text { Machining time }(\mathrm{min} .)}$

Tool wear rate after machining $=\frac{1000 \times \text { Weight loss }(\mathrm{gm})}{\text { Eectrode density }\left(\mathrm{gm} / \mathrm{cm}^{3}\right) \times \text { Machining time }(\mathrm{min} .)}$ each hole $\left(\mathrm{mm}^{3} / \mathrm{min}\right)$

With all the machining parameter mentioned in Table 3, diametrical overcut, taper angle, material removal rate and tool wear rate is found in case of the two specimens at different discharge current and presented in Table 4 .

TABLE IV. Machining responses at different discharge currents

\begin{tabular}{|l|l|l|l|l|l|l|l|l|}
\hline Specimen \# & $\begin{array}{l}\text { Current } \\
\text { (A) }\end{array}$ & $\begin{array}{l}\text { Machining } \\
\text { Time (min) }\end{array}$ & $\begin{array}{l}\text { Over } \\
\text { cut }\end{array}$ & $\begin{array}{l}\text { Taper } \\
\text { angle }\end{array}$ & $\begin{array}{l}\text { Difference in } \\
\text { metal weight } \\
\text { before and after } \\
\text { machining of } \\
\text { each hole in gm }\end{array}$ & $\begin{array}{l}\text { MRR per } \\
\text { hole in } \\
\text { inm } \mathbf{m i n}\end{array}$ & $\begin{array}{l}\text { Difference } \\
\text { in } \\
\text { weight after } \\
\text { tool } \\
\text { machining } \\
\text { each hole in } \\
\text { gm }\end{array}$ & $\begin{array}{l}\text { Tool wear } \\
\text { rate } \\
\text { machining } \\
\text { after } \\
\text { each hole in } \\
\text { mm }\end{array}$ \\
\hline 1 & 1.5 & 108 & 66.20 & 0.31 & $1.4 \mathbf{m}^{*} 10^{-3}$ & 0.00514 & 0.01442 & 0.0156 \\
\hline 2 & 1 & 163 & 62 & 0.53 & $1.84^{*} 10^{-3}$ & 0.00419 & 0.01054 & 0.0154 \\
\hline
\end{tabular}

As confirmed from the Table 4, with increase in current the machining time decreases, material removal rate (MRR) increases and tool wear also increases which hampers circularity of micro holes and in case of micro grooves its corner comes out to be little bit radial instead of sharp. The overcut is also higher in case of $1.5 \mathrm{~A}$ current than 1A. So, it is advisable to machine it at low current to get burr free surface.

Electrode wear can be clearly visualized from the micrographsshown in Fig. 8. Due to electrode wear the hole come out to be tapered along its length for which its inlet and exit diameters differ as depicted in Fig. 9 and Fig. 10. There may be secondary discharge during machining due to the presence of debris present in the hole as a result of which shape comes out to be little bit distracted at the exit. Due to the erosion on electrode tip in case of copper plate the grooves are not sharp in its corners rather its radial. The width also varies as the same 
electrode is used to make the grooves. These phenomena can be concluded from Fig. 11. Though the microstructure of the surface of groove shows a good surface finish still difficult to get proper dimension.
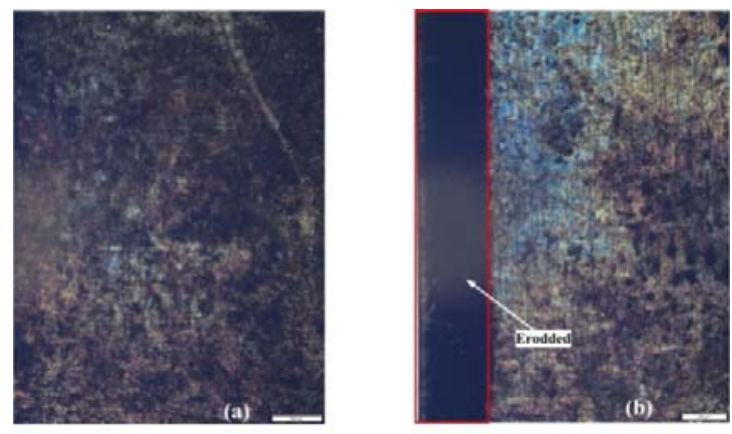

Fig. 8.STM image of (a) copper plate as electrode before machining and (b) after machining

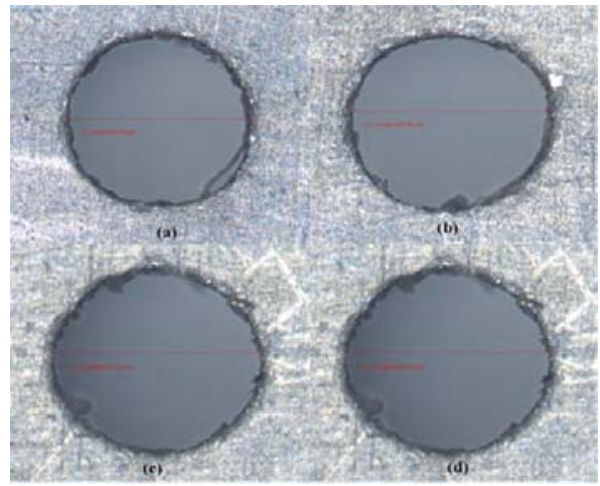

Fig. 9.Entry view of array of holes at $1 \mathrm{~A}$ current, gap voltage $50 \mathrm{~V}$ and pulse on time $50 \mu \mathrm{s}$

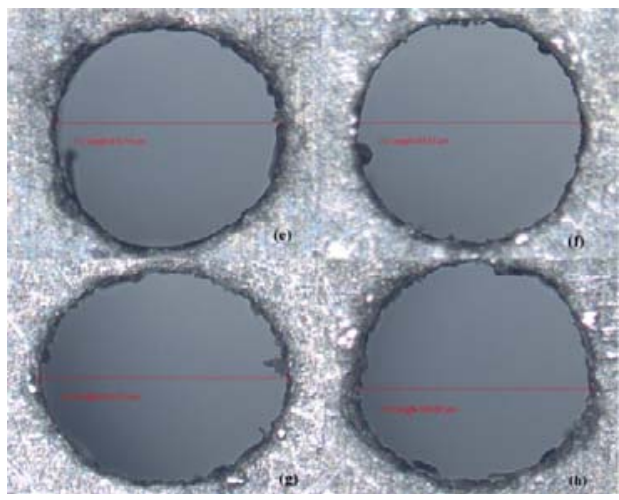

Fig. 10. Exit view of array of holes at $1 \mathrm{~A}$ current, gap voltage $50 \mathrm{~V}$ and pulse on time $50 \mu \mathrm{s}$

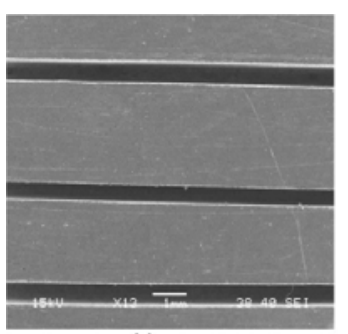

(a)

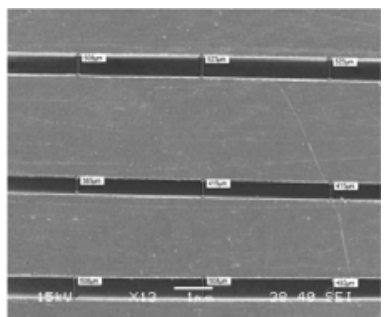

(b)

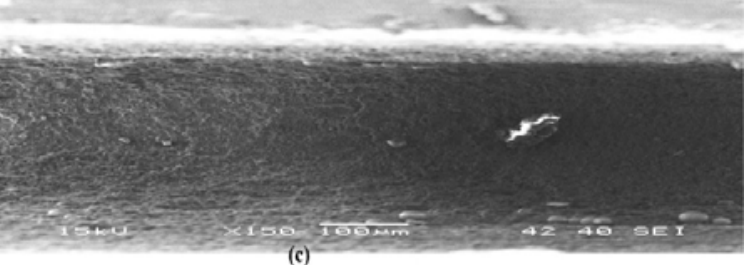

Fig. 11. SEM images of (a) microgrooves, (b) channel dimension taken at three different points along the length and (c) microstructure of channel along its length 


\section{CONCLUSION}

An extensive study is performed on the various tools used in micro EDM.Tools of different materials, shapes and dimensions have been used by many researchers for specific purposes during machining in micro EDM. Effort has been made to describe the procedure of fabricating microchannels like micro holes and micro grooves with least expenditure. The microchannels thus produced are compared with different operating conditions and important conclusions are made to improve its surface finish and accuracy. The machinability was compared on the basis of material removal rate, over cut, taper angel and tool wear.The electrode material seems to have a negligible effect on the final geometrical characteristics of the hole as well as the process parameters. Moreover, the copper based electrode has significant effect on the diametrical overcut due to vibration: this electrode material should be chosen to ensure a better repeatability of the experiments. The workpiece material properties (especially in terms of melting point), as well as the electrode material and geometry demonstrated to have a relevant effect on the surface finishing. In general, electrode and workpiece materials with high melting points ensure a better surface finishing.

\section{REFERENCES}

[1] L. Alting, F. Kimurta, H. N. Hansen and G. Bissacco, "Micro Engineering", Ann. CIRP Manuf. Technol.,Elsevier,vol. 52, pp. 635$658,2003$.

[2] Z. Katz and C. J. Tibbles, "Analysis of micro-scale EDM process", Int. J. Adv. Manuf. Tech..Springer, vol. 25, pp. 923-928, 2005

[3] S. Mahendran, R. Devarajan, T. Nagarajan, and A. Majdi,"A review of micro-EDM",Proceedings of the international multi conference of engineers and computer scientists, vol. 2,2010.

[4] S. Singh and A. Bhardwaj,"Review to EDM by using water and powder-mixed dielectric fluid", J. Miner. Mater. Charact. Engg.,Scientific Research, vol. 10, pp. 199-230, 2011.

[5] D. Reynaerts and H. Van Brussel,"Microstructuring of silicon by electro-discharge machining (EDM) - part I: theory",Sensors and Actuators A: Physical, vol.60, pp. 212-218, 1997.

[6] T. Masuzawa, "State of the art of micromachining",CIRP Ann Manuf. Techn., vol. 49, pp. 473-488, 2000.

[7] L. Raju and S. H. Somashekhar,"A state-of-the-art review on micro electro-discharge machining",Procedia Techno.,vol.25: pp. 1281$1288,2016$.

[8] K. P. Rajurkar, M. M. Sundaram and A. P. Malshe,"Review of electrochemical and electro-discharge machining",Proceedings of the Seventeenth CIRP Conference on Electro Physical and Chemical Machining (ISEM),Elsevier, vol. 6, pp. 13-26, 2013.

[9] K. P. Rajurkar, G. Levy, A. Malshe, M. M. Sundaram, J. McGeough, X. Hu, R. Resnick, and A. DeSilva,"Micro and nano machining by electro-physical and chemical processes", Ann. CIRP, Elsevier, vol. 55,pp. 643-666, 2006

[10] S. Dhanik, S. Joshi, N. Ramakrishnan and P. Apte,"Evolution of EDM process modelling and development towards modelling of the micro-EDM process", Int. J. Manuf. Technol. Manage., vol. 7, pp. 157,2005

[11] T. Sato, T. Mizutani andK. Kawata,"Electro-discharge machine for micro-hole drilling",Natl. Techn. Rep.,vol. 31,pp. 725-733, 1985.

[12] T. Masuzawa, M. Fujino, K. Kobayashi, T. Suzuki andN. Kinoshita,“Wire electro-discharge grinding for micro-machining”,CIRP Ann. Manuf. Techn.,vol. 34,pp. 431-434, 1985.

[13] K. Egashira andK. Mizutani, "Micro-drilling of monocrystalline silicon using a cutting tool”,Prec. Eng., vol. 26,pp. 263-268, 2002.

[14] S. H. Yeo andR. Nachiappan,"Investigation of electrodischarge micromachining controllable factors on machined silicon surface quality",Proc. Inst. Mech. Eng., B J. Eng. Manuf., vol.215,pp. 811-817, 2001.

[15] T. Masuzawa, J. Tsukamoto andM. Fujino,"Drilling of deep microholes by EDM”,CIRP Ann. Manuf. Techn.,vol. 38,pp. 195-198, 1989.

[16] T. Masaki, K. Kawata andT. Masuzawa,"Micro electro-discharge machining and its applications", In Micro Electro Mechanical Systems, Proceedings, An Investigation of Micro Structures, Sensors, Actuators, Machines and Robots. IEEE (21-26),1990.

[17] H. Liand T. Masaki, "Micro-EDM",ASME technical paper, MS91-485, pp. 1- 15, 1991.

[18] L.Li, Y. S. Wong, J. Y. H. Fuh and L. Lu "EDM performance of TiC/copper-based sintered electrodes." Materials \& Design 22, vol. 8, pp.669-678, 2001.

[19] M. B. Mohite andV. P. Gaikwad "Development of EDM Tool for Fabrication of Microchannel Heat Sink and Optimization of Single Response Parameter of EDM by Taguchi Method." International Journal, vol. 2, pp.63-70,2016.

[20] B. H. Yan, F .Y. Huang, H. M. Chowand J. Y. Tsai,"Micro-hole machining of carbide by electric discharge machining",J. Mater. Process.Tech.vol.87, pp.139-145,1999.

[21] Z. Y. Yu, K. P. Rajurkar and H. Shen, "High aspect ratio and complex shaped blind micro holes by micro EDM",CIRP AnnalsManufacturing Technology, vol.51, pp. 359-362, 2002.

[22] M. P. Jahan, Y. S. Wong and M. Rahman, "A study on the fine-finish die-sinking micro-EDM of tungsten carbide using different electrode materials",J. mater. Process. Tech., vol.209, pp.3956-3967, 2009.

[23] M.P.Jahan, M. Rahman and Y. S. Wong, "A review on the conventional and micro-electrodischarge machining of tungsten carbide",Int. J. Mach. Tool Manuf., vol.51, pp.837-858, 2011.

[24] H .S. Liu,B .H. Yan, F. Y. Huang and K. H. Qiu, "A study on the characterization of high nickel alloy micro-holes using micro-EDM and their applications", J. Mater. Process. Tech., vol. 169, pp.418-426, 2005.

[25] G. Kibria, I. Shivakoti andB. Bhattacharyya ,"Experimentation and Analysis into Micro-Hole Machining of Ti-6Al-4V by Micro-EDM Using Boron Carbide Powder Mixed De-Ionized Water"International Journal of Manufacturing, Materials, and Mechanical Engineering (IJMMME),vol.4, pp. 22-41, 2014.

[26] V. Gosavi, N. Phafat andS. Deshmukh,"Investigation of effect of process parameters in microhole drilling",IJMTER, vol. 6, pp.583587,2015 .

[27] K. P. Rajurkar andZ. Y. Yu, "3d micro-edm using CAD/CAM",CIRP Annals-Manufacturing Technology,vol. 49, pp.127-130,2000.

[28] T. Ishida and Y .Takeuchi, "L-shaped curved hole creation by means of electrical discharge machining and an electrode curved motion generator", Int. J. Adv. Manuf. Technol. , vol.19, pp. 260-265, 2002

[29] P. H. S Heeren, D. Reynaerts, H. V. Brussel, C. Beuret, O. Larsson andA. Bertholds,"Microstructuring of silicon by electro-discharge machining (EDM)-part II: applications",Sensors and actuators. A, Physical, vol. 61, pp. 379-386, 1997.

[30] T. A. Fofonoff, S .M. Martel, N. G. Hatsopoulos, J. P. Donoghue and I .W. Hunter, "Microelectrode array fabrication by electrical discharge machining and chemical etching",IEEE transactions on biomedical engineering,vol. 51, pp. 890-895, 2004.

[31] O. Yilmaz and M .A. Okka, "Effect of single and multi-channel electrodes application on EDM fast hole drilling performance", Int. J. Adv. Manuf. Techno., vol. 51, pp. 185-194, 2010. 
[32] C. C. Wangand B .H. Yan,"Blind-hole drilling of Al 2 O 3/6061 Al composite uses rotary electro-discharge machining",J. Mater. Process. Technology, vol. 102, pp. 90-102, 2000.

[33] H. S. Lim, Y. S. Wong, M. Rahman and M .E. Lee,"A study on the machining of high-aspect ratio micro-structures using microEDM",J. Mater. Process Tech, vol.140, pp.318-325, 2003.

[34] F. Han, Y. Yamada, T. Kawakami andM. Kunieda,"Experimental attempts of sub-micrometer order size machining using microEDM",PrecisionEngineering, vol30, pp.123-131, 2006.

[35] J .C. Hung, J .K. Lin, B. H. Yan, H. S. Liu and P .H. Ho,"Using a helical micro-tool in micro-EDM combined with ultrasonic vibration for micro-hole machining",J. Micromec. Microengg,vol. 16,pp. 2705, 2006.

[36] D. J. Kim, S .M. Yi , Y .S. Lee and C. N. Chu ,"Straight hole micro EDM with a cylindrical tool using a variable capacitance method accompanied by ultrasonic vibration",J. Micromech. Microeng., vol. 16, pp.1092, 2006.

[37] J. C. Hung, S .C. Lien, J .K. Lin, F .Y. Huang, \& B .H. Yan, "Fabrication of a micro-spherical tool in EDM combined with Nidiamond co-deposition", J. Micromech. andMicroeng", vol. 18, pp. 045010, 2008.

[38] C .K. Yang, J. C. Hung, C .P. Cheng, W. T. Lin, \& B. H. Yan,"Electrophoretic deposition characteristics of an electrical discharge machined micro-tool for micro-hole polishing in quartz",J. Micromech. Microeng., vol.20, pp.055031, 2010.

[39] G. Bissacco,J. Valentincic, H. N. Hansen, \& B .D. Wiwe,"Towards the effective tool wear control in micro-EDM milling",Int. J. Adv. Manuf. Technol.vol.47, pp. 3-9, 2010.

[40] F .T. Weng and M .G. Her, "Study of the batch production of micro parts using the EDM process",Int. J. Adv. Manuf. Technol., vol. 19, pp. 266-270, 2002.

[41] E. Uhlmann, G. Spur, N.A. Dausand U. Doll, "Application of micro-EDM in the machining of micro structured forming tools",SME Technical Paper MF99,pp.285, 1999.

[42] K. Takahata andY. B. Gianchandani," Batch mode micro-electro-discharge machining",Journal of Microelectromechanical systemsvol. 11, pp. $102-110,2002$.

[43] K. Takahata andY .B. Gianchandani, "Batch mode micro-EDM for high-density and high throughput micromachining ", Proceedings of the IEEE: MEMS, pp. 72-75, 2001.

[44] K. Takahata, N. Shibaike and H. Guekel,"A novel micro electro discharge machining method using electrodes fabricated by the LIGA process ", Proceedings of the IEEE: MEMS, pp. 238-243, 1999.

[45] N. Ravi andS. X. Chuan, "The effects of electro-discharge machining block electrode method for microelectrode machining",J. Micromech. Microeng., vol 12,pp. 532, 2002.

[46] N. Ravi and H .Huang, "Fabrication of Symmetrical Section Micro-features Using Electro-Discharge Machining Block Electrode Method", J. Micromech.Microeng. vol.12, pp. 905-910, 2000.

[47] S. T. Chen,"Fabrication of high-density micro holes by upward batch micro EDM",J. Micromech. Microeng.,vol 18, pp. 085002, 2008

[48] D.Y. Sheu, "High-speed micro electrode tool fabrication by a twin-wire EDM system",J. Micromech. Microeng., vol.18, pp. 105014, 2008.

[49] D.Y. Sheu,"Micro-spherical probes machining by EDM",J. Micromech. Microeng., vol15, pp.185, 2004.

[50] P. C. Kaminski andM. N. Capuano," Micro hole machining by conventional penetration electrical discharge machine", Int. J. Mach. Tools Manuf., vol.43, pp. 1143-1149, 2003.

[51] D.T. Pham, A. Ivanov, S. Bigot,K. Popovand S. Dimov,"An investigation of tube and rod electrode wear in micro EDM drilling",Int. J. Adv. Manuf. Techno., vol. 33, pp.103-109, 2007.

[52] C.K. Nirala andP. Saha,"Precise $\mu$ EDM-drilling using real-time indirect tool wear compensation",J. Mater. Process. Tech., vol. 240pp. 176-189, 2017.

\section{AUTHOR PROFILE}

Sasmita Bal obtained B.E. in Mechanical Engineering from University College of Engineering, Burla, India in the year 2004, M.Tech. in Thermal Engineering from National Institute of Technology, Rourkela, Odisha, India in the year 2010. She is currently working as an Assistant Professor in the School of Mechanical Engineering, KIIT University, Bhubaneswar, Odisha, India. Her research interests are impingement heat transfer, nanofluids, thermal systems design and optimization and computational fluid dynamics.

Purna Chandra Mishra obtained B.E. in Mechanical Engineering from Berhampur University, Odisha, India in the year 2001, M.Tech and PhD in Mechanical Engineering from Jadavpur University, Kolkata, India in the year 2006 and 2011. He is currently working as a Professor and Associate Dean in the School of Mechanical Engineering, KIIT University, Bhubaneswar, Odisha, India. His research interests are impingement heat transfer, nanofluids, thermal systems design and optimization, combustion engineering, biofuels and computational fluid dynamics.

Ashok Kumar Satapathy obtained B.E. in Mechanical Engineering from Berhampur University, Odisha, India in the year 1986, M.Tech in Thermal Engineering from IIT, Kharagpur, India in the year $1991 \mathrm{and} \mathrm{PhD}$ in Engineering from National Institute of Technology, Rourkela, Odisha, India in the year 2003. He is currently working as anAssociate Professorin the Department of Mechanical Engineering, NITRourkela, Odisha, India. His research interests are heat transfer, micro-fluids and computational fluid dynamics. 